Resource management in cardiovascular engineering: is outsourcing the solution?

Richard Feyrer, Michael Weyand and Udo Kunzmann

Perfusion 2005 20: 289

DOI: 10.1191/0267659105pf822oa

The online version of this article can be found at:

http://prf.sagepub.com/content/20/5/289

\author{
Published by: \\ (SAGE \\ http://www.sagepublications.com
}

Additional services and information for Perfusion can be found at:

Email Alerts: http://prf.sagepub.com/cgi/alerts

Subscriptions: http://prf.sagepub.com/subscriptions

Reprints: http://www.sagepub.com/journalsReprints.nav

Permissions: http://www.sagepub.com/journalsPermissions.nav

Citations: http://prf.sagepub.com/content/20/5/289.refs.html

>> Version of Record - Sep 1, 2005

What is This? 


\title{
Resource management in cardiovascular engineering: is outsourcing the solution?
}

\author{
Richard Feyrer ${ }^{1}$, Michael Weyand ${ }^{1}$ and Udo Kunzmann ${ }^{2}$ \\ ${ }^{1}$ Center of Cardiac Surgery, University of Erlangen-Nuremberg, Erlangen, Germany; \\ ${ }^{2}$ Center of Medicine Management, University of Erlangen-Nuremberg, Erlangen, Germany
}

In recent years, modern medicine has changed considerably. At maximum care centers, in particular, the use of state-of-the-art medical equipment has become an essential part of patient care. However, using such high-tech products also means a considerable burden on the financial resources available, because additional financing is rare. Consequently, there is a need for approaches that allow the use of state-of-the-art equipment without straining the budget unduly. The question now is whether

The German healthcare system is currently undergoing the largest financial crisis since the introduction of general medical insurance. The increasing amount of apparatus in medicine is leading to a drastic increase in costs on the one hand, while the diminishing premium revenues at the medical insurance companies offering statutory medical cover are leading to a significant reduction in the available financial resources on the other hand. The implementation of a new accounting system based on diagnosis related groups (DRGs) in the in-patient treatment sector is also putting hospitals, especially the maximum care high-tech clinics, in considerable difficulty. Due to the switch of reimbursement for in-patient hospital services from retrospective single-service reimbursement to prospective casefee reimbursement, the economic pressure on clinic management is growing. To be able to run a clinic economically in future, the average costs of the medical service must be below the average case-fee revenues. Only then can a positive revenue contribution be generated that is higher than the cost of the rendered service.

To date, hospitals were commercial operations in which the mechanisms of the market failed to apply. This was due, first, to the fact that the corporate objective of hospitals was not aimed at turnover maximization, but at the relevant medical care

Address for correspondence: Richard Feyrer, Center of Cardiac Surgery, University of Erlangen-Nuremberg, Krankenhausstr. 12, 91054 Erlangen, Germany.

E-mail: richard.feyrer@herz.imed.uni-erlangen.de economic strategies that have long since been established in other industries, e.g., the outsourcing of certain services, represent a potential solution for the economic problems of modern clinics. The fundamentals of outsourcing and its pros and cons are outlined and discussed, taking cardiovascular perfusion as an example, a cost-intensive field of heart surgery that is responsible for attending to heart-lung machines, artificial hearts and circulatory support systems. Perfusion (2005) 20, 289-294.

mission, and secondly, free pricing was prevented by a lack of financial transactions between the patient and the clinic. All the capital investment costs, running costs and treatment costs were reimbursed to the clinics, so the focus was not on rendering health services on a minimum cost basis. ${ }^{1}$ Upon the introduction of a case-fee form of payment for services, one is now pursuing the objective of creating a price-controlled incentive system, and, consequently, a near-market situation, in order to boost efficiency and cost-effectiveness in the hospitals. ${ }^{2,3}$ For this purpose, efficiency reserves of highly specialized facilities must be liberated without jeopardizing the quality level for patients. Against this background, German clinics see themselves increasingly confronted with the 'make or buy' (MoB) question, i.e., outsourcing, within the scope of management of the available financial resources. ${ }^{4}$ This particularly applies to the highly specialized, costly medical subdisciplines like heart surgery, including cardiovascular perfusion, which has undergone an enormous change in terms of staffing and technical resources within a few years. ${ }^{5,6}$

\section{Resource management}

In order to manufacture a product or render a service, it is necessary to employ production factors. These production factors represent the required resources. Business administration regards resources as all the operational input and production factors, i.e., the largely disaggregated, unspecific, 
homogeneous inputs that can be obtained by everyone through markets on the same conditions. Furthermore, they also include all the assets and special items that distinguish a company from other companies in the industry, and can, thus, represent the basis for a competitive advantage. Possible classifications are:

- internally generated resources and external resources;

- tangible resources and intangible resources;

- financial resources, physical resources, organizational resources, technological resources and human resources.

In contrast with this, macroeconomics divides resources into land, labor and capital.

If one now endeavors to apply this classification to cardiovascular perfusion, it results in a number of divisions that are involved in the cardiovascular perfusion 'service'. They center on operation of the heart-lung machine (HLM) with the required material resources and the perfusionist required to operate it. In addition, the financial resources tied up by the HLM and the human resources, i.e., perfusionists, in the form of experience and know-how, also have to be considered, detached from any financial evaluation in the form of payroll expenditure. In the following, resource management will be regarded as the most efficient handling of these essential, company-specific assets, along with the identification, exploitation, maintenance and (further) development of resources and potentials.

Nowadays, cardiovascular perfusion is a highly specialized activity with a high level of capital commitment, both in terms of fixed costs and variable costs. The area of fixed costs is determined by the cost of acquisition and maintenance of the HLM as well as payroll expenditure. ${ }^{\text {a }}$ The variable costs involve the material costs incurred in connection with the operation of the HLM. If cardiovascular perfusion is regarded as a pure service, the company is more and more frequently being presented with the issue of internal or external procurement (outsourcing) in order, for example, to bring about a shift of fixed costs into the variable area. The following paragraphs will deal with this issue in greater detail in light of specific aspects of cardiovascular perfusion.

\footnotetext{
${ }^{\text {a }}$ Payroll expenditure is regarded as medium-term fixed cost.
}

\section{Outsourcing: new road to the future}

\section{What is outsourcing?}

There are extremely different definitions and interpretations of the term outsourcing. Originally, the term stems from American economic life and it is an abbreviation of 'Outside Resource Using'. Generally speaking, it denotes that company services or company functions, of any kind whatsoever, are delegated to external specialists, i.e., are bought in from them. ${ }^{7}$ This delegation process can be geographically related, product-related or function-related, and combinations of these criteria are also feasible. Outsourcing refers to the complete separating-off of parts of the company, both legally and commercially. If this separating-off is not to take place completely, it is possible to implement preliminary stages, e.g., strategic alliances or joint ventures. The present article is concerned with the complete separating-off (legally and commercially) of HLM operation.

In this connection, there is also frequent talk of MoB decisions, although they must be distinguished from the term outsourcing, both materially and temporally. MoB is the generic term that refers to products and services, whereas outsourcing, as part of an MoB decision, normally refers to services. Outsourcing decisions always involve services already being rendered within the organization while MoB decisions are frequently taken before the development of a product. However, a distinct differentiation of these terms is difficult in practice. Outsourcing decisions are always long term so they are of strategic importance and it is their aim to bring about cost benefits (profit maximization) or long-term competitive advantages. There can also be other objectives, e.g.,

- conversion from fixed costs to variable costs;

- quality improvement through external specialists;

- cost reduction;

- personnel problems and personnel procurement;

- application of different scales of charges outside of the German Federal Collective Agreement for Public Employees, 'BAT'.

If one examines the concept of outsourcing under the conditions of financing by standard case fees (DRGs), it is even being intensified because, if there is a reduction in costs, higher profits can be achieved, which have to be used to finance loss-making areas.

\section{Variants of outsourcing}

As mentioned already, outsourcing is used to pursue various objectives. Hence, there are also different 
variants of outsourcing, of which two will be discussed here. Firstly, there is contractual outsourcing in the service sector and co-operative agreements with other institutions.

Service outsourcing. In outsourcing in the service sector, a clinic-specific contract is prepared which is limited by time. The contracting parties are the clinic and the external company offering the service. In the case of service outsourcing, the benefits to the hospital are as follows:

1. The campaign is of limited duration.

2. No major personnel changes are required during that period.

3. Compliance with the contract and the service provider's performance can be tested.

4. Low-cost solution.

If, after a test phase, it should turn out that the pursued objectives are being achieved and the other party to the contract is meeting its obligations, it is possible to aim for total outsourcing. At this point, it is also possible for the contracting parties to introduce contractual adjustments. Consequently, outsourcing of the HLM can be 'tested' over a defined period and a response can be provided for any inappropriate developments. The drafted contract concerning operation of the HLM regulates, for example, the material resources occurring within the scope of an uncomplicated bypass grafting operation. The standard level of consumption is defined for various interventions, thus, aiming to restrict the risk for the service provider, e.g., in the event of complications during the intervention. If, during the test phase, it becomes evident that the defined standard level of consumption is too low, this can be taken into account in ensuing contractual negotiations. Moreover, contractual lower limits and upper limits can be defined for HLM deployments in order to improve planning certainty.

Co-operation with other institutions. Co-operation with other institutions is a hybrid form of outsourcing and it denotes the placement of contracts, for instance, logistics services, for several hospitals in the region with an external service provider. The objective is, for example, to provide the individual hospitals with supplies on a 'just-in-time' basis from a central goods distribution center. The purchasing departments of the various hospitals act like a joint venture and can, thus, obtain high discounts due to economies of scale.

\section{Contract drafting}

Contract drafting in the area of outsourcing represents a central point because this is where decisions frequently are already taken concerning the costs and benefits of outsourcing. The outsourcing contract is the documentation of the outsourcing project in legal terms. Its importance lies in the establishment and assessment of the various implementation stages and clear definitions to avoid ambiguities. It is, therefore, necessary to exercise special caution and involve the affected employees, who are best suited to appraising the existing problems and ones arising. The outsourcing agreement should form the basis to prevent disputes and differences of opinion. It must, therefore, conform to the individual, specific requirements of the outsourcing enterprise and contain the legal contractual fundamentals for longer-term cooperation. The essential elements of a contract are master agreements concerning the principles of cooperation and a detailed description of services.

An outsourcing agreement should cover the following issues:

- objects of the agreement

- type of agreement, legal status of the partners

- terms of the agreement

- conditions of the agreement

- flow chart for organization and procedure

- contractual amendment

- delimitation of services, catalogue of requirements

- definition of spheres of responsibility

- description of rendered service/quality

- definition of the scope of service

- liability, warranty, indemnification

- nonperformance clauses

- terms of payment

- coverage of risk elements

- definition of opting-out criteria and rights of withdrawal

- contract termination

- items required for individual cases

- etc.

If, in outsourcing, it is intended that personnel be taken over by the outsourcing partner, there needs to be a detailed arrangement conforming to legal regulations, which is agreed with the employee involved. 


\section{Viability analysis}

\section{Decision-making criteria}

Decisions concerning internal and external procurement are frequently taken for the short term, chiefly on a purely cost basis. One result of this is inadequate full cost comparisons in which qualitative issues and opportunity costs are only rarely considered. The objective must, therefore, be to consider and evaluate all the accruing (direct and indirect) costs. Three methods of decision making are outlined below.

\section{Break-even analysis}

Make-or-buy decisions are of a strategic nature. As a result, all the costs accruing for external procurement must be compared with the cost of internal production. Here, all the resulting costs must be considered, i.e., not only material costs and payroll costs, but also depreciation, capital costs, maintenance costs, venture costs and calculated entrepreneurial income, etc. ${ }^{8}$ A mere analysis of costs, though, is inadequate for the assessment of an investment decision, because the revenue side must always be taken into consideration as well. If the forecast income situation is known for the hospital and if information is available on the forecast variable and fixed costs, the break-even analysis can be used to determine the so-called break-even point. This point denotes the output from which the hospital reaches the profit zone. Relative to the outsourcing decisions in the sector of cardiovascular perfusion, this point specifies the number of HLM deployments from which external procurement or internal production is worthwhile. Both alternatives are considered equal. ${ }^{9}$ If one assumes that, as from a certain number of HLM deployments, the variable costs decrease due to economies of scale, for example, the break-even point indicates from what number of machines upward internal production is worthwhile. In terms of business administration, a comparison of the revenue and cost functions is conducted, whereby the intersection (break-even point) denotes the point from which revenues exceed costs.

\section{Capital commitment}

If one examines capital commitment when outsourcing in the field of cardiovascular perfusion, the endeavor is to transfer fixed-cost-intensive procurement of the HLM to the external source. As a result, capital flexibility is achieved within one's own company because the fixed-cost base is reduced. In order to consider this process in more detail, it is necessary to examine some other ratios, e.g., return on equity or return on investment (ROI). In the case of ROI, one restricts profit to the operating result and capital input to the operationally required assets. ${ }^{10}$ However, this will not be explained in any greater detail here.

\section{Qualitative considerations}

One problem with strategic make-or-buy decisions across a relatively large time horizon is the extremely hypothetical cost-calculation approach because future developments are difficult to forecast. In order to eliminate this planning uncertainty, there has been a switch recently towards introducing so-called argument balances for or against internal or external procurement. Here, only the advantages and disadvantages of a procurement alternative are compared initially. If this argument balance is refined by focusing on important points (weighting), a strengths-and-weaknesses portfolio can be developed from it. It is also referred to as a weighted benefit analysis. The qualitative internal/external analysis allows an objective appraisal of a procurement problem for which no specific, or vague, figures are available from cost accounting.

\section{Outsourcing: two sides of the coin}

In modern literature, the term 'outsourcing' is defined in very different ways. In the field of clinic management, outsourcing refers to the long-term separating-off of certain functions, as well as the resources required for function performance, from the commercial process, and delegation of these to third parties. The depth and impact of outsourcing depends essentially on the outsourcer's degree of integration into the company and the extent to which the functions are separated off. ${ }^{11}$ The decision in favor of outsourcing should always be planned in the long term, so it is of considerable strategic significance. The objective is to bring about cost advantages (profit maximization) or long-term competitive advantages, whereby the cost-cutting potentials, especially in the service sector, are due to the fact that, in future, payroll costs will tend to rise more steeply than material costs. ${ }^{12,13}$ As long as the principle of cost coverage was applied in hospital financing, there was no need for clinics to separate off certain subdisciplines. However, new concepts in the field of financing and management also require new organizational structures.

\section{Advantages of outsourcing}

If one examines the advantages of outsourcing, the picture obtained varies, whereby, in the field of 
cardiovascular perfusion, there are four different fields of consideration: strategic factors, performance factors, cost factors and personnel factors. In terms of strategic aspects, one argument in favor of outsourcing cardiovascular perfusion is the concentration on core business, i.e., primary operative patient treatment, the transfer of risks (investment risk, especially internal procurement of several HLMs, circulatory support systems, etc.) to the service company, standardization of structures and flexible response to changes (change in operation figures or in the range of services). In terms of performance aspects, important issues are the fast availability of professional manpower (well trained, experienced cardiovascular perfusionists) and stateof-the-art equipment, as well as the feasibility of new plans and projects (product switchover, introduction of innovative techniques) without internal restriction. Furthermore, with outsourcing, it is possible to achieve considerable cost reductions, especially within the operation (reduction in payroll costs and material costs). In particular, fixed costs can be converted to variable costs. This increases the cost awareness for cardiovascular perfusion as a subdiscipline.

\section{Disadvantages of outsourcing}

The largest risk in the field of outsourcing is the possibility of hasty, insufficiently planned separating-off strategies. In strategic terms, outsourcing is bad if the clinic is exposed to considerable dependence on the service company and it loses too much internal know-how. The hospital can also be confronted with disadvantages if the partner becomes insolvent or legal disputes arise. A frequent change of personnel and use of cheap products must be avoided by drafting the contract accordingly. These factors, in particular, tend to have an enormous influence on quality in the field of cardiovascular perfusion and heart surgery. Other disadvantages of outsourcing can be a loss of economic advantages due to optimization or efficiency-boosting measures at the hospital and an amendment to the contractual terms in the event of a long term of agreement.

\section{Cost-benefit analysis of the Erlangen model}

For the past five years, cardiovascular engineering at Erlangen University Clinic has practiced a combination model of outsourcing and in-house solutions. The senior perfusionist and one further colleague are salaried employees of the university clinic, while three perfusionists, as well as the entire

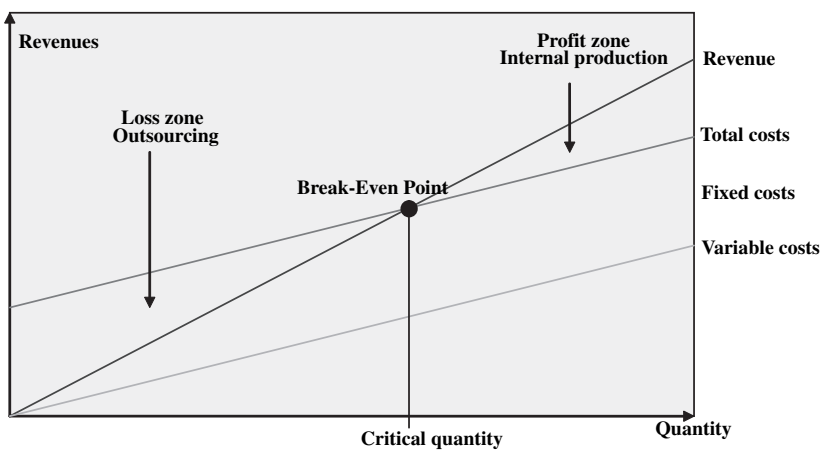

Figure 1 Break-even analysis. The break-even point indicates from what number of deployed HLMs internal production is worthwhile.

equipment and material requirements, are outsourced to the company WKK-Perfusionsservice.

This combination model is aimed at multiplying the advantages of both these individual solutions while simultaneously minimizing the disadvantages. The results of the cost-benefit analysis reveal that the outsourcing model is profitable up to a total volume of 1752 operations in which a HLM is deployed (Figures 1 and 2).

It shows the different cost lines and the points of intersection for calculation of the break-even point. Line $Y_{f}$ represents the fixed costs with the function $Y_{\mathrm{f}}=€ 491911$. Line $Y_{\mathrm{v}}$ represents the variable costs with the function $Y_{v}=1306 x$. This means that each deployment of the HLM in Erlangen involves variable costs amounting to €1306, while the annual fixed costs amount to $€ 491911$. Line $Y_{\mathrm{g}}$ represents the course of the total costs with the function $\mathrm{Y}_{\mathrm{g}}=$ $1306 x+491911$. Line $Z_{1}$, with the function $Z_{1}=$ 1586.89x, shows the course of the costs sustained if HLM deployment is outsourced. The increase of these lines indicates the price level (€1586.89/ HLM), i.e., the flatter the line, the lower the price per HLM.

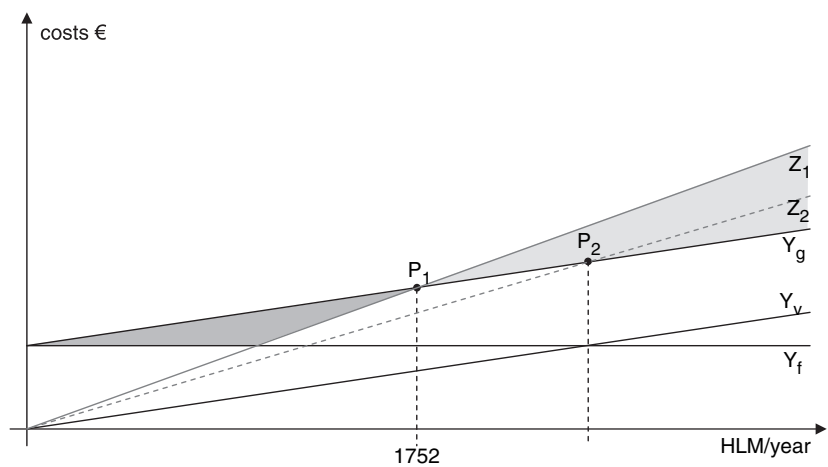

Figure 2 Representation of the different cost lines and the points of intersection for calculation of the break-even point in the Erlangen combination model. 
To calculate the break-even point, Line $\mathrm{Y}_{\mathrm{g}}$ has to be co-ordinated with $\mathrm{Z}_{1}$ and resolved in accordance with the unknown variable $\mathrm{x}$. That calculation results in a break-even point of 1751.23 , i.e., as from a quantity of 1752 HLM deployments per annum, in-house deployment of the HLM is more cost effective than outsourcing. This sector is represented by the area E. However, it should be noted that, as the outsourced quantity increases, it is often possible to negotiate better contractual terms with the company concerned, i.e., as from a quantity of 1300 HLM deployments per annum, the price per machine decreases by $10 \%$. For Line $Z_{1}$, this would mean that the curve would decrease, so that the line is flatter and the break-even point moves towards the right. This situation is demonstrated by Line $\mathrm{Z}_{2}$ and Point $\mathrm{P}_{2}$.

\section{Prospects}

The field of cardiovascular engineering has changed dramatically during the course of its development. Both in the personnel sector and in terms of equipment, this has led to an enormous increase in incurred costs due to professionalization and advancement. In addition, there is increasing cost

\section{References}

1 Breyer F. Preisbildung und Vergütung im stationären Sektor. In Anderson H, Graf v.d. Schulenburg JM, Henke K-D eds. Basiswissen Gesundheitsökonomie, Volume 1, Berlin Edition Sigma, 1992: 93-109.

2 Bijkerk JA. Die neue BPflV - eine strategische Herausforderung für das Krankenhausmanagement. Das Krankenhaus 1994; 86: 456-60.

3 Bolles W. 'Markt' für Krankenhausleistungen - Realität oder Wunschvorstellung? Das Krankenhaus 1994; 86: $60-65$.

4 Hensley S. Outsourcing moves into new territory. Mod Healthc 1997; 27: 39-40, 42-3.

5 Lautenbach G. Geschichtlicher Rückblick - Entwicklungen in der Kardiotechnik. In Tschaut RJ ed. Extrakorporale Zirkulation in Theorie und Praxis. Berlin: Pabst Science Publishers, 1999.

6 Böttcher W, Merkle F, Weitkemper H-H. Historische Entwicklung des kardiopulmonalen Bypasses von der Idee zur Anwendung. Kardiotechnik 2003; 12: $44-54$. pressure for hospital institutions with ever-declining resources. What are now the future prospects for cardiovascular perfusion in economic terms?

Everyday practice will be characterized by cost saving and efficiency boosting as trendsetting factors. However, in such an essential area as modern heart surgery, this must not take place at the expense of quality. Well-trained cardiovascular perfusionists and state-of-the-art equipment must continue to be standard for any heart surgery unit in the future. The question that any hospital institution must ask itself is, therefore, how can the required quality of cardiovascular perfusion be provided with the specified financial resources at minimal cost?

This question cannot be answered in a generalized way. Outsourcing, with all its variants (total, only personnel or equipment, purchasing, etc.) can be one possible approach. However, an in-house solution with an appropriate clinic structure also represents a practicable, economic solution. Clarity regarding the most favorable solution in each case can ultimately only be provided by appropriate costbenefit analyses based on reliable cost unit accounting. Unfortunately, these basic prerequisites of strategic planning are either still very limited at many clinics, especially in the university sector, or they are not available at all.
7 Schneck O. Lexikon der Betriebswirtschaft, fifth, completely revised and enlarged edition. Munich, 2003.

8 Gerke W, Bank M. Finanzierung, Grundlagen für die Investitions- und Finanzierungsentscheidungen in Unternehmen, first edition. Stuttgart, 1998.

9 Schöffski O, Graf v.d. Schulenburg J-M. Gesundheitsökonomische Evaluationen, second, completely revised edition. Berlin, 2000.

10 Schmalen H. Grundlagen und Probleme der Betriebswirtwschaft, eleventh, completely revised and enlarged edition. Stuttgart, 2001.

11 Böckenhoff N. Einbindung und Ausgliederung. In Jeschke H, Hailer B ed. Outsourcing im Klinikbereich. Kulmbach, 2001, 19-22.

12 Reibnitz C. Veränderte Umfeldbedingungen erfordern strategische Planung. Führen und Wirtschaften 1996; 13: $544-49$.

13 Bliesener M-M. Outsourcing als mögliche Strategie zur Kostensenkung. Betriebswirtschaftliche Forschung und Praxis 1994; 46: 277-90. 